\title{
Research on the influence of science popularization on regional innovation ability
}

\author{
Qian $\mathrm{Li}^{1, \mathrm{a},{ }^{*}}$ \\ ${ }^{1}$ Beijing Jiaotong University, Beijing, China \\ a16120514@bjtu.edu.cn \\ * Qian Li
}

Keywords: science popularization, regional innovation ability, panel data.

\begin{abstract}
Science popularization (simply named SP) is the foundation and premise of technological innovation. This paper bases on the panel data from 2010 to 2015 of 31 provinces in China, establishes an indices system of Regional SP ability evaluation index from 5 aspects. On this basis, we use the two-way fixed effect model to examine the impact of popular science service on regional innovation ability in China. The results show that SP service has a positive impact on China's overall regional innovation capability. Meanwhile, there is obvious regional heterogeneity: the impact of SP on the second regions is the most significant, and it is not significant for the first or third regions. The study of this paper provides some empirical evidence for reducing the regional innovation gap by strengthening the construction of SP ability.
\end{abstract}

\section{Introduction}

The report of 19th CPC National Congress pointed out that science and technology are the first productive forces, and innovation is the first driving force to lead the development. Scientific and technological innovation is the key to improve the comprehensive competitiveness of the country, and SP is the basis and prerequisite for technological innovation. In the new era, our government still attaches great importance to the development of popular science, and vigorously promotes the development of SP and industrialization. It can be seen that popular science plays an important role in improving the scientific literacy of citizens and improving the ability of innovation.

At present, domestic scholars mainly focus on the theoretical level of the relationship between science and innovation, and few scholars have examined the relationship between them empirically. The theoretical analysis have good references, but there are still shortcomings: although some scholars to evaluate the ability of Science in China, but no scholars use the comprehensive ability of science services on the regional innovation ability of empirical research. Therefore, this paper uses the panel data to establish the regional SP ability evaluation index from 5 aspects and according to the calculation result divides provinces into three kinds of areas. On this basis, the two-way fixed effect model is used to empirically investigate the impact of SP service on China's regional innovation capability, and it has a certain reference significance for the development of SP service in China.

\section{Measurement of the ability of Regional SP}

\subsection{Evaluation index system of SP ability}

In order to reflect our regional SP ability, based on the research of existing scholars, 9 indicators are selected from five aspects of popular science, popular science infrastructure, popular science funding, popular science creation and popular science activities to measure regional SP ability. 
Table 1 Evaluation index of SP ability

\begin{tabular}{cc}
\hline Primary indexs & Secondary indexes \\
\hline SP workers & Every ten thousand people have a full-time staff \\
\cline { 2 - 2 } & Every ten thousand people have a part-time job \\
\hline SP infrastructure & Number of science and technology libraries per million people \\
\cline { 2 - 2 } & Area of every 10000 people's science and Technology Museum \\
\hline The input of the SP founds & The ratio of SP founds to GDP \\
\hline The creation of SP & The number of SP books' types for every 10000 people \\
\cline { 2 - 2 } & The total number of SP books published for every 10000 people \\
\cline { 2 - 2 } SP activities & The number of SP events for every 10000 people \\
\hline
\end{tabular}

\subsection{Evaluation steps based on entropy weight method}

This paper based on the 2010-2015 of the 31 provincial panel data as the research object, using entropy method to quantify the ability of provincial SP, get the comprehensive evaluation of regional SP ability.

\subsubsection{Data standardization processing}

As the measurement unit, dimension and meaning of the above evaluation index are different, the data must be standardized before the comprehensive evaluation. In this paper, the membership degree method is used to standardize the data, and the methods are as follows:

$$
r_{i j}=\frac{x_{i j}-\min _{1 \leq j \mathrm{n}} x_{i j}}{\max _{1 \leq j \leq n} x_{i j}-\min _{1 \leq j \leq n} x_{i j}}
$$

$x_{i j}$ is the value of the $\mathrm{j}$ evaluation index on the index $\mathrm{i}$, and $\mathrm{n}$ is the number of the evaluated objects.

\subsubsection{Calculation weight based on entropy weight method}

According to the average SP service level of 2010-2015 provinces in the whole province, 31 provinces are divided into the following three categories.

Table 2 Classification Based on the capacity of popular science service

\begin{tabular}{ccc}
\hline Classification & Standard & Areas \\
\hline $1^{\text {st }}$-level areas & $\begin{array}{c}\text { Comprehensive } \\
\text { level }>0.15\end{array}$ & $\begin{array}{c}\text { Beijing, Shanghai, Hainan, Qinghai, Ningxia,Xinjiang, Zhejiang, } \\
\text { Hubei, Tianjin, Inner Mongolia, Yunnan, Jiangsu, Shaanxi, }\end{array}$ \\
\hline $2^{\text {nd }- \text { level areas }}$ & $\begin{array}{c}0.05<\text { Comprehensive } \\
\text { level<0.15 }\end{array}$ & $\begin{array}{c}\text { Fujian, Chongqing, Tibet, Liaoning, Jiangxi, Gansu, Shanxi, } \\
\text { Guizhou, Sichuan, Guangxi, Guangdong and Anhui. }\end{array}$ \\
\hline $3^{\text {rd }- \text { level areas }}$ & $\begin{array}{c}\text { Comprehensive level } \\
<0.05\end{array}$ & Jilin, Shandong, Hunan, Heilongjiang, Hebei and Henan \\
\hline
\end{tabular}

\section{Data description and empirical analysis}

\subsection{Variable selection}

Dependent variable: Patent data is widely adopted by many related studies because of its relatively perfect information, comparability and easy access. Therefore, this paper selects the patent admissibility of every ten thousand people in each region to measure regional innovation ability.

Independent variables: because the content of popular science is much more involved, it is difficult to measure the development level of the service ability of a region by one or more of them. Therefore, this paper builds a comprehensive index of 5 aspects based on the research of other scholars.

Control variables: in this paper, we use the level of human capital, the government's support, the degree of openness and the development of technology market as control variables. 
Table 3 Descriptive statistics of the variables

\begin{tabular}{ccccc}
\hline Variables & Mean & SD & Min & Max \\
\hline Lnzla & 1.923264 & 1.139686 & -0.61619 & 4.276666 \\
\hline Pops & 0.120293 & 0.163871 & 0.018344 & 0.964248 \\
\hline Edu & 0.118422 & 0.063931 & 0.023913 & 0.42335 \\
\hline Gov & 0.018416 & 0.013861 & 0.003045 & 0.065844 \\
\hline Open & 0.291889 & 0.28282 & 0.04733 & 1.639374 \\
\hline Tech & 0.010537 & 0.024055 & 0 & 0.150074 \\
\hline
\end{tabular}

\subsection{Empirical analysis}

In order to test the influence of SP service capability on regional innovation capability and regional heterogeneity, we set the following regression equation.

$$
\ln _{\text {la }}=\alpha+\beta \text { pops }_{i t}+\gamma X_{i t}+\mu_{i}+v_{t}+\varepsilon_{i t}
$$

\subsubsection{The overall impact of SP service capability on regional innovation capability}

According to the regression results obtained in Table 4, we see that the results of the Hausmen test reject the original hypothesis, and we should choose the fixed effect model, so we only look at the regression results of (1) and (3). The regression coefficients of the SP service capacity variables are always positive regardless of whether or not the control variables are added, and all are significant at the level of $10 \%$. This indicates that the promotion of our SP service capability does bring a significant increase in the output of innovation.

The other control variables: the regression coefficient of Edu and Tech are all negative, which is contrary to expectation, but not statistically significant, indicating that both of them have limited influence on regional innovation ability, it may be due to these factors need to be improved. The regression coefficients of Gov and Open are all positive, and the government support is obviously positive, indicating that the government's financial scientific and technological expenditure can significantly promote the improvement of regional innovation level.

Table 4 Influence of SP service capability on regional innovation capability

\begin{tabular}{|c|c|c|c|c|}
\hline & (1) & (2) & (3) & (4) \\
\hline & FE & RE & FE & $\mathrm{RE}$ \\
\hline \multirow[t]{2}{*}{ Pops } & $1.008^{*}$ & -0.747 & $0.92 *$ & $-3.853 * * *$ \\
\hline & (1.93) & $(-0.97)$ & (1.67) & $(-6.12)$ \\
\hline \multirow[t]{2}{*}{ Edu } & & & -0.120 & $9.743 * * *$ \\
\hline & & & $(-0.18)$ & $(7.43)$ \\
\hline \multirow[t]{2}{*}{ Gov } & & & $12.009 *$ & $47.409 * * *$ \\
\hline & & & (1.94) & $(7.47)$ \\
\hline \multirow[t]{2}{*}{ Open } & & & 0.106 & 0.058 \\
\hline & & & $(0.33)$ & $(0.20)$ \\
\hline \multirow[t]{2}{*}{ Tech } & & & -3.900 & 7.678 \\
\hline & & & $(-0.91)$ & $(1.50)$ \\
\hline $\mathrm{R}^{2}$ & 0.978 & 0.891 & 0.979 & 0.579 \\
\hline $\mathrm{N}$ & 186 & 186 & 186 & 186 \\
\hline Hausman test & \multicolumn{2}{|c|}{$\begin{array}{c}\text { Chi-Sq. Statistic }=14.79 \\
\text { Prob }=0.0001\end{array}$} & \multicolumn{2}{|c|}{$\begin{array}{c}\text { Chi-Sq. Statistic }=20.47 \\
\text { Prob }=0.001\end{array}$} \\
\hline
\end{tabular}

Note: $* * * * *$ and $*$ represent the significant level of $1 \%, 5 \%$ and $10 \%$ respectively. The same below.

\subsubsection{The regional heterogeneity of the impact of SP service capability}

According to the previous article, 31 provinces are divided into three types of areas. Then the paper returns to three types of regions to investigate whether the areas with different science and technology services are heterogeneous, and the results are shown in Table 5. 
Table 5 regional heterogeneity regression results

\begin{tabular}{|c|c|c|c|}
\hline & \multicolumn{3}{|c|}{ Classification } \\
\hline \multirow{3}{*}{ Pops } & $1^{\text {st }}$ level areas & $2^{\text {nd }}-$ level areas & $3^{\text {rd }}$-level areas \\
\hline & 0.780 & $3.556 * * *$ & $-5.417 * *$ \\
\hline & $(0.61)$ & $(3.04)$ & $(-2.32)$ \\
\hline Control variable & YES & YES & YES \\
\hline Provincial effect & YES & YES & YES \\
\hline Time effect & YES & YES & YES \\
\hline $\mathrm{R}^{2}$ & 0.989 & 0.979 & 0.984 \\
\hline $\mathrm{N}$ & 30 & 120 & 36 \\
\hline
\end{tabular}

It can be found that there is a great difference in the influence of SP service capacity on regional

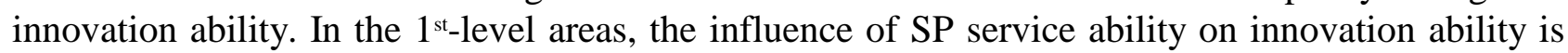
positive, but it is not significant. In the $2^{\text {nd }}$-level areas, it is significant. In the $3^{\text {rd }}$-level areas, it is significant negative. This paper argues that the reasons for such regional heterogeneity may be due to the fact that in $1^{\text {st-level }}$ areas, SP service capacity has been relatively perfect and the level of innovation is relatively high, so the marginal influence of SP service capacity on regional innovation ability is weakened, and the influence range is relatively limited; in the $2^{\text {nd }}-$ level areas, SP has begun to take shape, but there is still a lot of room for promotion. In this stage, it is easy to improve the scientific literacy of regional citizens through SP, so as to promote the production of scientific and technological achievements and improve regional innovation ability. In the $3^{\text {rd }}$-level area, the level of SP is very low so the SP has no positive influence on the promotion of innovation ability, but the innovation ability of the government finance and technology expenditure on regional innovation are obviously positive, which shows that this kind of region is more easy to improve the regional innovation ability through the government's support.

\section{Main conclusions and policy implications}

The conclusions and policy implications are as follows:

First, from the overall regression results, the influence of SP service ability on regional innovation ability is positive. It shows that the improvement of SP service ability is beneficial to promote the production of scientific and technological achievements and promote the enhancement of regional innovation ability. At present, our country has entered the new period of economic development, it is necessary to seize the opportunity and realize the overtaking of the curve at the time of the new industrial revolution, not only to support the development of the emerging industries, and to raise the scientific literacy of the whole people. We should continue to further strengthen the infrastructure of SP and the construction of SP information.

Second, there is regional heterogeneity in the impact of SP service capacity on regional innovation ability. Only in the $2^{\text {nd }}$-level areas, SP service capacity has a significant positive impact on regional innovation ability. This shows that it can promote the innovation power of the region through the promotion of popular SP in this kind of region. In the 1st-level areas, the ability of SP service has been improved well, so the degree of impact is relatively limited. In the $3^{\text {rd }}$-level areas, the influence of SP service capacity on regional innovation ability is negative and significant. The reason is that the level of SP is very low, which is equivalent to the level of entry. So government can promote the construction of science and technology services according to the actual situation in various regions.

Third, in the Internet age, the scale of Internet users is expanding. The traditional media has been unable to meet people's need. It is necessary to strengthen the construction of SP information and upgrade of the whole SP work. For the SP service itself, it should be combined with the trend of the development of the times, innovate the traditional SP way, make SP by the way of innovation, and 
make SP through the communication mode of the Internet. The combination of SP and Internet will accelerate the popularization of SP.

\section{References}

[1] Wang K, Xie X, Zhou J. Science Popularization under the Era of Internet [J]. Studies on Science Popularization, 2017.

[2] W.Q. Liang, C.H. Liu, C.Y. Yang. Research on Innovation Effect of Human Capital Based on Heteroscedastic Stochastic Frontier Model[J].Science \& Technology Process and Policy, 2016, 33 (15): 145-150.

[3] Cheung, K.Y and Lin, P.. Spillover Effects of FDI on Innovation in China: Evidence from the Provincial Data[J]. China Economic Review, 2004, 15,(1).

[4] C.Y. Hou, C.X. Yang. Research on correlation between science popularization input and national innovation capacity[J].China Science \& Technology Resources Review, 2016,48(2):99-104.

[5] Ren R, Zheng N, Gang X. Research on correlation between science popularization and technological progress[J]. Science Research Management, 2013:2907-2912.

[6] Ren R, Zhen N, Zhao M. Evaluation on Regional Science Popularization Capacity: Based on Entropy-GEM[J]. Technology Economics, 2013. 